OPEN ACCESS

Edited by:

Rupert Langer,

University of Bern, Switzerland

Reviewed by:

Mirko Omejc,

University Medical Centre

Ljubliana, Slovenia

Savio George Barreto,

Medanta - The Medicity, India

Alexander R. Novotny,

Klinikum rechts der Isar der

Technischen Universität München,

Germany

${ }^{*}$ Correspondence:

Binay Kumar Shah

binay.shah@gmail.com

Specialty section:

This article was submitted to

Gastrointestinal Cancers,

a section of the journal

Frontiers in Oncology

Received: 24 January 2016

Accepted: 23 March 2016

Published: 11 April 2016

Citation:

Shah BK, Khanal A and Hewett Y (2016) Second Primary Malignancies in Adults with Gastric Cancer - A US

Population-Based Study.

Front. Oncol. 6:82.

doi: 10.3389/fonc.2016.00082

\section{Second Primary Malignancies in Adults with Gastric Cancer - A US Population-Based Study}

\author{
Binay Kumar Shah ${ }^{1 *}$, Amit Khanal ${ }^{2}$ and Yvonne Hewett ${ }^{1}$ \\ ${ }^{1}$ PeaceHealth United General Medical Center, Lewiston, ID, USA, ${ }^{2}$ Section of Hematology and Oncology, Department of \\ Medicine, University of Illinois at Chicago, Chicago, IL, USA
}

Background: Multiple studies have examined the incidence of secondary primary malignancies (SPMs) in gastric cancer patients in Europe and Asia. This retrospective review was conducted to analyze risk of SPM in patients with gastric cancer diagnosed in the United States.

Methods: We included adult patients diagnosed with gastric cancer from the surveillance, epidemiology, and end result (SEER) 13 database. We calculated the risk of SPMs in these patients using the multiple primary standardized incidence ratio session of SEER*stat software and performed subset analyses of SPM with regard to age, sex, radiotherapy used, and latency period.

Results: Among 33,720 patients, 1838 (5.45\%) developed 2019 SPMs with an observed/ expected $(\mathrm{O} / \mathrm{E})$ ratio of 1.11 [95\% confidence interval $(\mathrm{Cl})=1.06-1.16, p<0.001$ ] and an absolute excess risk of 18.16 per 10,000 population. The median time to first SPM from the time of diagnosis of gastric cancer was 46.9 months (range 6-239 months). Significant excess risk was observed for gastrointestinal malignancies [O/E ratio 1.71 $(\mathrm{Cl}=1.59-1.84, p<0.001)]$, thyroid [O/E ratio $2.00(\mathrm{Cl}=1.37-2.8, p<0.001)]$, and pancreatic cancer [O/E ratio $1.60(\mathrm{Cl}=1.29-21.96, p<0.001)]$. Risk of secondary melanoma, breast cancer, and prostate cancer was lower than in the general population.

Conclusion: The risk for SPMs is significantly increased in adults with gastric cancer compared to the general population.

Keywords: gastric cancer, second primary malignancy, SEER, latency

\section{INTRODUCTION}

Gastric cancer is the fifth most common cancer and the third leading cause of cancer-related death worldwide. The highest incidences are found in Eastern Asia and Central and Eastern Europe (1). Although the incidence of gastric cancer has declined over the last half century, the prognosis remains poor (2).

The majority of patients in the United States (US) present with regional or distant metastases, with an overall 5 -year survival rate of $28.3 \%$ (1). By contrast, most Japanese gastric cancer patients are diagnosed in early stages of the disease and have an overall 5-year relative survival rate of over $50 \%(3)$. 
Geographic disparities exist in treatment modality as well (4). Surgery remains the only potentially curative option (5). Although multimodal treatment is the standard of care for bulky localized disease, adjuvant chemotherapy is typically employed in Asia, adjuvant chemoradiation in North America, and neoadjuvant chemotherapy in European and Australasian nations (4). Patients with advanced or recurrent disease typically receive systemic chemotherapy, as it provides a survival advantage over other treatments (6).

Gastric cancer survivors are at risk for secondary primary malignancies (SPMs). This long-term complication was first described by Warren and Gates in 1932 (7). Synchronous malignancies are defined as occurring with 6 months of the primary diagnosis, whereas metachronous tumors occur more than 6 months after the initial event. The risk of SPM is dependent on factors including patient age, cancer stage at diagnosis, and treatment modality (8).

The risk of SPM in gastric cancer patients in the US is unknown. Given the global variations in gastric cancer incidence, treatment, and survival, we evaluated the risk of SPMs in adult gastric cancer patients in the US to determine if geographic disparities are present. In addition, increased awareness of SPMs will provide the framework for pilot intervention studies and the development of evidence-based guidelines for gastric cancer survivors.

\section{METHODOLOGY}

\section{About SEER Database}

These data represent $14 \%$ of the US population, including the geographical areas of Atlanta, Connecticut, Detroit, Hawaii, Iowa, Los Angeles, New Mexico, rural Georgia, San FranciscoOakland, San Jose-Monterey, Seattle (Puget Sound region), Utah, and Alaska Natives (1). Comprehensive cancer data, including primary tumor site, staging, patient demographics, treatment, and survival from hospitals and cancer treatment facilities, are subjected to rigorous quality control studies, resulting in a mature database, with $98 \%$ case completeness.

\section{Study Population}

We selected adult patients aged 18 years or more, diagnosed with gastric cancer as first primary malignancy from January 1992 to December 2012. Patients were followed from diagnosis to the date of last known vital status, death, or the last point of data collection. We excluded cases diagnosed at autopsy and those lost to follow-up. Using the Warren and Gates criteria (7) as modified by the NCI (9), SPM was defined as metachronous malignancy developing 6 months or more after an index gastric carcinoma.

\section{Data Analysis}

We used SEER ${ }^{\star}$ stat software, Version 8.2.1 April 8, 2015 to calculate the standardized incidence ratio (SIR), absolute excess risk (AER), and confidence interval (CI) for SPM in patients, as previously diagnosed with gastric cancer. We analyzed that the risks of SPM by latency period (6-23 versus 24 months or more) and exposure to radiotherapy were determined.
The SIR, which is also known as the relative risk, is a relative measure of the strength of association between two cancers. It is calculated by dividing the observed incidence of SPM by the expected incidence of SPM [observed/expected (O/E) ratio] in the general population. AER is an absolute measure of the clinical burden of additional cancer per 10,000 occurrences in the population. It measures the actual number of excess events normalized to the number of person years observed $[\mathrm{AER}=(\mathrm{O}-\mathrm{E}) \mathrm{PY}]$.

\section{RESULTS}

A total of 33,720 patients diagnosed with primary gastric cancer met the study criteria. Patient demographics are presented in Table 1. A total of 1838 patients (5.26\%) developed 2019 SPMs with an $\mathrm{O} / \mathrm{E}$ ratio of 1.11 ( $\mathrm{CI}=1.06-1.16, p<0.001$; AER 18.16) (Table 2). A total of 1676 patients developed 1 SPM, and 162 developed 2 or more SPMs. The average age at diagnosis of SPM was 74 years (24-104 years). The median time from primary diagnosis to development of first SPM was 46.9 months (range 6-239 months). Significant excess risk was observed for gastrointestinal, biliary, pancreatic, and thyroid cancers. Significantly, decreased risk was observed for secondary melanoma, breast, and prostate cancer.

\section{SPM and Age}

All patients had an increased risk of gastrointestinal second primary malignancies. On subgroup analysis, older patients had

\begin{tabular}{|c|c|}
\hline & Number $(\%) / m e d i a n$ (range) \\
\hline Total number of patient with gastric cancer & 33,720 \\
\hline \multicolumn{2}{|l|}{ Gender } \\
\hline Male & $20,474(60.72 \%)$ \\
\hline Female & $13,246(\%)$ \\
\hline \multicolumn{2}{|l|}{ Race } \\
\hline White & 22,451 (66.58\%) \\
\hline Black & 3942 (11.69\%) \\
\hline Other & 7327 (21.73\%) \\
\hline Total number of SPM & 2019 \\
\hline Total number of patient with SPM & 1838 (5.45\% of study population) \\
\hline Total number of patient with 1 SPM & 1676 (4.97\% of study population) \\
\hline \multicolumn{2}{|l|}{ Gender } \\
\hline Male & $1084(64.68 \%)$ \\
\hline Female & $592(35.32 \%)$ \\
\hline \multicolumn{2}{|l|}{ Race } \\
\hline White & $1126(67.18 \%)$ \\
\hline Black & $210(12.53 \%)$ \\
\hline Other & $340(20.29 \%)$ \\
\hline Total number of patient with 2 or more SPM & 162 \\
\hline \multicolumn{2}{|l|}{ Gender } \\
\hline Male & 115 (70.99\%) \\
\hline Female & 47 (29.01\%) \\
\hline \multicolumn{2}{|l|}{ Race } \\
\hline White & $112(69.14 \%)$ \\
\hline Black & $22(13.58 \%)$ \\
\hline Other & $28(17.28 \%)$ \\
\hline $\begin{array}{l}\text { Age at the time of diagnosis of SPM } \\
\text { (median) }\end{array}$ & 74 years ( 24.3 years -104.5 years) \\
\hline Latency to develop first SPM & 3.91 years (6 months-19.91 years) \\
\hline Follow-up time (median) & 6.91 years (6 months-20.91 years) \\
\hline
\end{tabular}


TABLE 2 | Total SPM

\begin{tabular}{|c|c|c|c|c|c|}
\hline & \multicolumn{5}{|c|}{ Total } \\
\hline & \multicolumn{5}{|c|}{$\begin{array}{c}\text { Person at risk }=33,720 \\
\text { Person year at risk }=107,690.38\end{array}$} \\
\hline & $N$ & O/E & $\begin{array}{l}\text { Two } \\
\text { tail } p\end{array}$ & $\begin{array}{l}\text { Confidence } \\
\text { interval }\end{array}$ & $\begin{array}{c}\text { Excess } \\
\text { risk }\end{array}$ \\
\hline All sites & 2019 & 1.11 & $<0.001$ & $1.06-1.16$ & 18.16 \\
\hline $\begin{array}{l}\text { All sites excluding non- } \\
\text { melanoma skin }\end{array}$ & 2011 & 1.11 & $<0.001$ & $1.06-1.16$ & 18.16 \\
\hline All solid tumors & 1813 & 1.12 & $<0.001$ & $1.07-1.18$ & 18.54 \\
\hline Brain and other CNS tumor & 12 & 0.74 & 0.349 & $0.38-1.29$ & -0.4 \\
\hline Head and neck & 36 & 0.62 & 0.002 & $0.43-0.85$ & -2.07 \\
\hline Thyroid & 33 & 2 & $<0.001$ & $1.37-2.8$ & 1.53 \\
\hline Lung and bronchus & 299 & 1.09 & 0.153 & $0.97-1.22$ & 2.26 \\
\hline Esophagus & 51 & 2.41 & $<0.001$ & $1.79-3.17$ & 2.77 \\
\hline Stomach & 217 & 4.51 & $<0.001$ & $3.93-5.16$ & 15.69 \\
\hline Small intestine & 24 & 3.06 & $<0.001$ & $1.96-4.55$ & 1.5 \\
\hline Colon, rectum, and anus & 254 & 1.15 & 0.03 & $1.01-1.3$ & 3.11 \\
\hline $\begin{array}{l}\text { Liver, gallbladder, and other } \\
\text { biliary }\end{array}$ & 69 & 1.3 & 0.04 & $1.01-1.65$ & 1.48 \\
\hline Pancreas & 92 & 1.6 & $<0.001$ & $1.29-1.96$ & 3.19 \\
\hline Breast & 124 & 0.8 & 0.011 & $0.67-0.95$ & -2.89 \\
\hline Female genital system & 64 & 1.07 & 0.615 & $0.82-1.37$ & 0.4 \\
\hline Male genital system & 300 & 0.79 & $<0.001$ & $0.7-0.88$ & -7.41 \\
\hline Urinary system & 182 & 1.11 & 0.173 & $0.95-1.28$ & 1.68 \\
\hline Soft tissue including heart & 10 & 1.05 & 0.964 & $0.5-1.93$ & 0.04 \\
\hline $\begin{array}{l}\text { Skin excluding basal and } \\
\text { squamous }\end{array}$ & 40 & 0.64 & 0.003 & $0.46-0.87$ & -2.09 \\
\hline Lymphoma & 76 & 0.95 & 0.709 & $0.75-1.19$ & -0.37 \\
\hline Myeloma & 27 & 0.97 & 0.97 & $0.64-1.41$ & -0.08 \\
\hline Acute lymphocytic leukemia & 3 & 2.08 & 0.352 & $0.43-6.08$ & 0.14 \\
\hline $\begin{array}{l}\text { Chronic lymphocytic } \\
\text { leukemia }\end{array}$ & 15 & 0.73 & 0.261 & $0.41-1.21$ & -0.51 \\
\hline Acute myeloid leukemia & 22 & 1.44 & 0.122 & $0.9-2.18$ & 0.63 \\
\hline Chronic myeloid leukemia & 11 & 1.71 & 0.126 & $0.85-3.06$ & 0.42 \\
\hline Kaposi sarcoma & 3 & 2.06 & 0.357 & $0.43-6.03$ & 0.14 \\
\hline
\end{tabular}

a significantly higher risk of SPMs of the esophagus $(\mathrm{O} / \mathrm{E}$ ratio of $2.28, \mathrm{CI}=1.67-3.06, p<0.0001$; AER 3.15), stomach $(\mathrm{O} / \mathrm{E}$ ratio of $3.66, \mathrm{CI}=3.13-4.26, p<0.0001$; AER 15.11), small intestine $(\mathrm{O} / \mathrm{E}$ ratio of 2.93, $\mathrm{CI}=1.81-4.48, p<0.0001$; AER 1.72$)$, thyroid $(\mathrm{O} / \mathrm{E}$ ratio of $1.95, \mathrm{CI}=1.25-2.9, p<0.005$; AER 1.45), and pancreas $(\mathrm{O} / \mathrm{E}$ ratio of $1.55, \mathrm{CI}=1.24-1.92, p<0.001$; AER 3.77). Younger patients were at increased risk of malignancies of lung and bronchus $(\mathrm{O} / \mathrm{E}$ ratio of 2.05, $\mathrm{CI}=1.36-2.96, p<0.001$; AER 5.24), esophagus $(\mathrm{O} / \mathrm{E}$ ratio of $4.05, \mathrm{CI}=1.49-8.81, p<0.001$; AER $1.65)$, stomach $(\mathrm{O} / \mathrm{E}$ ratio of $20.56, \mathrm{CI}=15.26-27.11, p<0.0001$; AER 17.39), colon (O/E ratio of 2.91, $\mathrm{CI}=2.09-3.95, p<0.0001$; AER 9.84), and urinary system $(\mathrm{O} / \mathrm{E}$ ratio of $2.47, \mathrm{CI}=1.57-3.71$, $p<0.001$; AER 5).

\section{SPM and Latency}

The median time from primary diagnosis to development of first SPM was 47 months (range 6-229 months). All solid tumors were significantly increased after 24 months of latency $(\mathrm{O} / \mathrm{E}$ ratio of $1.18, \mathrm{CI}=1.12-1.24, p<0.001$; AER 30.42). The risk of malignancies of thyroid (O/E ratio of 3.17, $\mathrm{CI}=1.77-5.22, p<0.001$; AER
3.08), esophagus $(\mathrm{O} / \mathrm{E}$ ratio of $2.52, \mathrm{CI}=1.44-4.09, p<0.005$; AER 2.89), and small intestine (O/E ratio of 4.03, $\mathrm{CI}=1.84-7.64$, $p<0.005$; AER 2.03) was significantly increased within 6-23 months of the index diagnosis. The risk of malignancies of esophagus $(\mathrm{O} / \mathrm{E}$ ratio of $2.36, \mathrm{CI}=1.64-3.28, p<0.0001$; AER $2.71)$, stomach $(\mathrm{O} / \mathrm{E}$ ratio of $5.34, \mathrm{CI}=4.59-6.17, p<0.0001$; AER 19.9), small intestine (O/E ratio of 2.67, $\mathrm{CI}=1.49-4.4$, $p<0.005$; AER 1.26), hepatobiliary system (O/E ratio of 1.54 , $\mathrm{CI}=1.17-1.99, p<0.005$; AER 2.79), pancreas $(\mathrm{O} / \mathrm{E}$ ratio of $1.69, \mathrm{CI}=1.32-2.13, p<0.0001$; AER 3.84), and lung and bronchus $(\mathrm{O} / \mathrm{E}$ ratio of $1.18, \mathrm{CI}=1.03-1.34, p<0.05$; AER 4.69) was increased after 24 months of latency compared to the general population.

\section{SPM and Radiation Exposure}

Of the 1838 patients who developed SPM, 421 received radiotherapy. The risk of SPM at all sites was significant in both groups. Among patients with no radiation exposure, the risk of SPMs of the thyroid $(\mathrm{O} / \mathrm{E}$ ratio of $1.69, \mathrm{CI}=1.06-2.56, p<0.05$; AER 1.06), esophagus $(\mathrm{O} /$ E ratio of $2.1, \mathrm{CI}=1.46-2.92, p<0.0001$; AER 2.16), stomach $(\mathrm{O} / \mathrm{E}$ ratio of $4.43, \mathrm{CI}=3.8-5.13, p<0.0001$; AER 16.04), small intestine $(\mathrm{O} / \mathrm{E}$ ratio of $3.17, \mathrm{CI}=1.94-4.9, p<0.0001$; AER $1.61)$, and pancreas $(\mathrm{O} / \mathrm{E}$ ratio of $1.52, \mathrm{CI}=1.19-1.91, p<0.005$; AER 2.9) was significantly increased. Patients with exposure to radiation had increased the risk of thyroid $(\mathrm{O} / \mathrm{E}$ ratio of 3.13 , $\mathrm{CI}=1.56-5.6, p<0.005$; AER 3.3), esophagus (O/E ratio of 3.57, $\mathrm{CI}=2.04-5.8, p<0.0001 ;$ AER 5.08), stomach (O/E ratio of 4.96, $\mathrm{CI}=3.56-6.73, p<0.0001$; AER 14.44), large bowel (O/E ratio of $1.52, \mathrm{CI}=1.16-1.96, p<0.005$; AER 8.92), and pancreas $(\mathrm{O} / \mathrm{E}$ ratio of $1.96, \mathrm{CI}=1.2-3.02, p<0.01$; AER 4.31).

\section{DISCUSSION}

There are currently more than 13 million cancer survivors in the US, with a projected increase to 18 million by 2022 (10). Early diagnosis and development of new agents continue to improve cancer outcomes. Long-term morbidity and premature mortality may occur in survivors, as a result of comorbidities, treatment, or disease-related factors.

In 2006, the Institute of Medicine report recommended the use of evidence-based guidelines to identify and manage the long-term effects of cancer, including surveillance for and prevention of recurrences and SPMs (11). Studies such as this not only increase awareness of secondary malignancies but also provide valuable information that may be used to pilot interventions in care leading to improved outcomes for cancer survivors. SPMs are common in cancer patients with an overall cumulative incidence of $14 \%$ at 25 years of follow-up (12).

Previously published literature has examined the incidence of SPMs in gastric cancer patients in Asia, Europe, and the Middle East. This is the first study to examine the incidence of SPM in gastric cancer patients in the US. Previous studies are inconsistent regarding the risks for SPM in gastric cancer, but our results are in agreement with the literature that suggests an increased risk for colon, liver, and pancreatic cancers 
(13-17). Many gastric cancer patients may receive radiotherapy, a known risk factor for secondary malignancies. A recent cohort study estimated the excess risk at $8 \%$ in patients surviving more than 1 year following treatment, resulting in 5 SPMs per 1000 radiotherapy patients by year 15 after diagnosis (18). We have summarized rates of SPMs reported in the literature (Table 3). Our study is the largest study in the last 25 years. Contrary to the study by Hiyama et al., our study showed significant increase in risk of SPM in gastric cancer patients. Findings of our study will help us formulate evidence-based guidelines for follow-up of gastric cancer survivors.

The strengths of this study include its large sample size and long-term follow-up. The limitations of the study are related to the use of population-based registries. Surveillance, epidemiology, and end result (SEER) database does not have comorbidities, lifestyle and risk factors, environmental exposure, and family history. SEER database does not have information on chemotherapy used. We were unable to analyze SPM by stage, because collaborative stage is not used for cases diagnosed prior to 2004 (19).

The risk of SPM is significantly increased in US patients with gastric cancer. The risk of any specific SPM is dependent on treatment and time of latency. Evaluation for SPMs is critical in the follow-up of gastric cancer survivors.

\section{REFERENCES}

1. Available from: http://seer.cancer.gov/statfacts/html/stomach.html

2. Bollschweiler E, Berlth F, Baltin C, Mönig S, Hölscher AH. Treatment of early gastric cancer in the Western World. World J Gastroenterol (2014) 20(19):5672-8. doi:10.3748/wjg.v20.i19.5672

3. Matsuda T, Saika K. The 5-year relative survival rate of stomach cancer in the USA, Europe and Japan. Jpn J Clin Oncol (2013) 43(11):1157-8. doi:10.1093/ jico/hyt166

4. Merrett N. Multimodality treatment of potentially curative gastric cancer: geographical variations and future prospects. World J Gastroenterol (2014) 20(36):12892-9. doi:10.3748/wjg.v20.i36.12892

5. Orditura M, Galizia G, Sforza V, Gambardella V, Fabozzi A, Laterza MM, et al. Treatment of gastric cancer. World J Gastroenterol (2014) 20(7):1635-49. doi:10.3748/wjg.v20.i7.1635

6. Kanagavel D, Fedyanin M, Tryakin A, Tjulandin S. Second-line treatment of metastatic gastric cancer: current options and future directions. World J Gastroenterol (2015) 21(41):11621-35. doi:10.3748/wjg.v21.i41.11621

7. Warren S, Gates O. Multiple primary malignant tumors: a survey of the literature and a statistical study. Am J Cancer (1932) 16:1358-414.

8. Heroiu Cataloiu AD, Danciu CE, Popescu CR. Multiple cancers of the head and neck. Maedica (Buchar) (2013) 8(1):80-5.

9. Available from: http://ctep.cancer.gov/protocolDevelopment/electronic applications/docs/aeguidelines.pdf

10. Cowens-Alvarado R, Sharpe K, Pratt-Chapmen M, Willis A, Gansler T, Edge SB, et al. Advancing survivorship care through the National Cancer Survivorship Resource Center. CA Cancer J Clin (2013) 63:147-50. doi:10.3322/caac.21183

11. Hewitt M, Greenfield S, Stoval E. From Cancer Patient to Cancer Survivor: Lost in Transition. Washington, DC: National Academies Press (2006).

12. Yang J, Terebelo $\mathrm{H}$, Zonder J. Secondary primary malignancies in multiple myeloma: an old nemesis revisited. Adv Hematol (2012) 2012:801495. doi:10.1155/2012/801495
TABLE 3 | Second primary malignancies in gastric cancer.

\begin{tabular}{lccc}
\hline Reference & $\begin{array}{c}\text { Number of } \\
\text { patients }\end{array}$ & $\begin{array}{c}\text { Number of } \\
\text { SPM }\end{array}$ & $\begin{array}{c}\text { Odd's ratio } \\
\mathbf{( 9 5 \% ~ C l ) ~}\end{array}$ \\
\hline Hiyama et al. (14) & 61,168 & 1045 & M: $0.84(0.78-0.90)$ \\
& 34,506 & 962 & $1.16(1.09-1.24)$ \\
Lundegardh et al. (15) & 2250 & 47 & $\mathrm{~N} / \mathrm{A}$ \\
Ikeda et al. (16) & 105 & 10 & $\mathrm{~N} / \mathrm{A}$ \\
Bozzetti et al. (13) & 1070 & 54 & $\mathrm{~N} / \mathrm{A}$ \\
Ikeda et al. (17) & 33,720 & 2019 & $1.11(1.06-1.16)$ \\
Current study & & &
\end{tabular}

N/A, not available; SPM, second primary malignancies; $M$, male; $F$, female

$\mathrm{Cl}$, confidence interval.

\section{AUTHOR CONTRIBUTIONS}

BS: concept/hypothesis, data acquisition, interpretation, and analysis; drafting of manuscript. $\mathrm{AK}$ and $\mathrm{YH}$ : data analysis and interpretation, critical revision for intellectual content; drafting of manuscript.

\section{AUTHOR NOTE}

This paper was presented as a poster at Gastrointestinal Cancers Symposium, January 15-17, 2015 at San Francisco.

13. Bozzetti F, Bonfanti G, Mariani L, Miceli R, Andreola S. Early gastric cancer: unrecognized indicator of multiple malignancies. World J Surg (2000) 24:583-7. doi:10.1007/s002689910097

14. Hiyama T, Hanai A, Fujimoto I. Second primary cancer after diagnosis of stomach cancer in Osaka, Japan. Jpn J Cancer Res (1991) 82:762-70. doi:10.1 111/j.1349-7006.1991.tb02700.x

15. Lundegardh G, Hansson LE, Nyren O, Adami HO, Krusemo UB. The risk of gastrointestinal and other primary malignant diseases following gastric cancer. Acta Oncol (1991) 30:1-6. doi:10.3109/02841869109091804

16. Ikeda Y, Saku M, Kawanaka H, Nonaka M, Yoshida K. Features of second primary cancer in patients with gastric cancer. Oncology (2003) 65:113-7. doi:10.1159/000072335

17. Ikeda Y, Saku M, Kishihara F, Maehara Y. Effective follow-up for recurrence or a second primary cancer in patients with early gastric cancer. Br J Surg (2005) 92:235-9. doi:10.1002/bjs.4758

18. Berrington de Gonzales A, Curtis RE, Kry SF, Gilbert E, Lamart S, Berg CD, et al. Proportion of second cancers attributable to radiotherapy treatment in adults: a cohort study in the US SEER cancer registries. Lancet Oncol (2011) 12(4):353-60. doi:10.1016/S1470-2045(11)70061-4

19. Available from: http://training.seer.cancer.gov/collaborative/system/

Conflict of Interest Statement: The authors declare that the research was conducted in the absence of any commercial or financial relationships that could be construed as a potential conflict of interest.

Copyright $\odot 2016$ Shah, Khanal and Hewett. This is an open-access article distributed under the terms of the Creative Commons Attribution License (CC BY). The use, distribution or reproduction in other forums is permitted, provided the original author(s) or licensor are credited and that the original publication in this journal is cited, in accordance with accepted academic practice. No use, distribution or reproduction is permitted which does not comply with these terms. 